\title{
Estimated Stabilization Costs of the EMU
}

\author{
Ray C. Fair*
}

A multicountry econometric model and stochastic simulation are used to estimate the stabilization costs of the European Monetary Union (EMU). A measure of the variability of output and other variables is computed for the current regime and for the EMU regime. The results show that Germany is burt the most in terms of increased output variability in moving from the current regime to the EMU regime.

\section{Introduction}

When different countries adopt a common currency, each gives up its own monetary policy. In the common-currency regime monetary policy responds to a shock in a particular country only to the extent that the common monetary authority responds to the shock. If this response is less than the response that the own country's monetary authority would have made in the pre common-currency regime, there are stabilization costs of moving to a common currency. This article estimates the stabilization costs to European countries of adopting a common currency. The multicountry econometric (MC) model in Fair (1994) and stochastic simulation are used for this purpose. Variability estimates are computed for the current regime and for the regime that is assumed to exist if a common currency is adopted. ${ }^{(1)}$

The question that this article attempts to answer is a huge one, and the present results are at best exploratory. In order to answer this question one needs 1 ) an estimate of how the current world economy operates, 2) an estimate of how it would operate if the European countries adopted a common currency, and 3) an estimate of the likely shocks to the world economy. Each of these estimates in this article is only an approximation, and work with other approximations is needed before much confidence can be placed on the current conclusions. The main aim of this article, aside from presenting some initial cost estimates, is to propose a methodology for answering this question.

There is a rapidly growing literature on analyzing the economic consequences of a common European currency. Wyploz (1997) provides a useful recent review. Much of this literature is in the Mundell (1961), McKinnon (1963), and Kenen (1969) framework and asks whether Europe meets the standards for an optimum currency area. The questions asked include how open the countries are, how correlated individual shocks are across countries, and the degree of labour mobility. There is also recent work exam- ining real exchange rate variances. The smaller are these variances, the smaller are the likely costs of moving to a common currency. In a recent study von Hagen and Neumann (1994) compare variances of price levels within West German regions with variances of real exchange rates between the regions and other European countries.

The MC model that is used for the results in this article contains estimates of how open countries are in that there are estimated import demand equations and estimated trade-share equations in the model. The model also contains estimates of the correlation of individual shocks across countries through the estimated error terms in the individual equations. Real exchange rates are endogenous because there are estimated equations for nominal exchange rates and individual country price levels. The coefficients of all these equations are estimated in traditional ways (by 2SLS or OLS); no calibration is done. ${ }^{(2)}$ The MC model thus has embedded in it estimates of a number of the features of the world economy that are needed to analyze optimum-currency-area questions. The degree of labour mobility among countries, however, is not estimated: the specification of the model is based on the assumption of no labour mobility among countries. To the extent that there is labour mobility, the present stabilization-cost estimates are likely to be too high.

A key feature of the MC model for present purposes is that there are estimated monetary-policy rules for each of the main countries. These take the form of estimated interest rate reaction functions. In the EMU regime these rules for the European countries are replaced with one ruleone interest rate reaction function for all of Europe. There are also estimated exchange rate equations for each of the main countries in the model (except for the United States, which is the base country). In the EMU regime these equations for the European countries are replaced with one equation-the exchange rate equation for the common European currency vis-à-vis the US dollar.

* Cowles Foundation, Yale University, New Haven, CT 06520-8281. Voice; 203-432-3715; Fax: 203-432-6167; e-mail: fair@econ.yale.edu; website: http://tairmodel.econ.yale.edu. A previous version of this paper was presented at an ESRC c nference on Macroeconomic Modelling and Economic Policy, London, 8-9 January 1998. All the data used in this paper can be downloaded tiom the website. I am indebted to William Nordhaus for many useful suggestions. 
Section 2 briefly outlines the MC model, and Section 3 explains the stochastic-simulation experiments. The variability estimates are then presented in Section 4 for the regular version of the model-the "current" regime. Section 5 discusses the changes that were made to the MC model to set up the "EMU" regime. This is the least data determined part of the article. Assumptions have to be made about the characteristics of the EMU regime, and many choices are possible. As a first cut I have assumed that all European countries join the EMU, and so the present estimates are conditional on this assumption. In future work it would be easy to use different subsets of countries, depending on what seemed most likely to happen. The general methodology is not restricted to using all the countries. The variability estimates are then presented in Section 6 for the EMU regime, and they are compared to the estimates in Section 4. Section 7 concludes with a discussion of some possible biases of the estimates.

Some of the results in this article are also related to the literature on policy coordination across countries. Using the methodology of this article it is possible to examine the effects of one country's policy behaviour on other countries, and this is briefly discussed at the end of Section 4.

\section{The MC Model}

There are 33 countries in the MC model. ${ }^{(3)}$ There are 31 stochastic equations for the United States and up to 15 each for the other countries. The total number of stochastic equations is 328 , and the total number of estimated coefficients is 1442 . In addition, there are 1041 estimated trade-share equations. The total number of endogenous and exogenous variables, not counting the trade shares, is about 4000 . Trade-share data were collected for 45 countries, and so the trade-share matrix is $45 \times 45 .^{(4)}$ An updated version of this model has been used for the present work, and this version is presented on the website mentioned in the introductory footnote.

The estimation periods begin in 1954:1 for the United States and as soon after 1960 as data permit for the other countries. They end between 1992 and 1994 except for the United States, where they end in 1997:1. The estimation technique is 2SLS except when there are too few observations to make the technique practical, where OLS is used. The estimation accounts for possible serial correlation of the error terms. The variables used for the first stage regressors for a country are the main predetermined variables in the model for the country. A list of these variables is available from the website. Since the MC model is discussed in detail in Fair (1994) and on the website, it will only be briefly outlined here. ${ }^{(s)}$

\section{The Estimated Equations}

On the demand side, there are estimated equations for consumption, fixed investment, inventory investment, and imports for each country. Consumption depends on income, wealth, and an interest rate. Fixed investment depends on output and an interest rate. Inventory investment depends on the level of sales and the lagged stock of inventories. The level of imports depends on income, wealth, the relative price of imported versus domestically produced goods, and an interest rate. The interest rate used for a given country and equation is either a short-term rate or a long-term rate, depending on which was more significant. The longterm rate is related to the short-term rate in each country through a standard term structure equation, where the long-term rate depends on the current value and lagged values of the short-term rate. A decrease in the short-term interest rate in a country leads to a decrease in the longterm rate, and interest-rate decreases have a positive effect on consumption, fixed investment, and imports.

There are estimated price and wage equations per country. A recent discussion of these equations can be found in Fair (1997a, 1997b). The domestic price level in a country depends, among other things, on a measure of demand pressure (usually an output-gap variable) and the price of imports.

As noted in Section 1, there is an estimated interest-rate reaction function for each country. The short-term interest rate depends on inflation, demand pressure, and the balance of payments. These are 'leaning against the wind' equations of the monetary authorities. The monetary authorities are estimated to raise short-term interest rates in response to increases in inflation and demand pressure and decreases in the balance of payments. The US short-term interest rate is an explanatory variable in a number of the other countries' reaction functions. This means that the United States is assumed to play a leadership role in setting monetary policy. Also, the German short-term interest rate is an explanatory variable in a number of the other European countries' reaction functions.

The variables that were chosen as explanatory variables in the interest rate reaction function for a given country were those whose coefficient estimates were of the expected sign and were statistically significant or close to being significant. The variables that were tried included current and past values of inflation, of various measures of demand pressure, and of the balance of payments. For some countries none of these variables were significant, which means that no evidence could be found that the monetary authority of that country leaned against the wind with respect to domestic variables. The four key European countries in this regard are Austria, France, Belgium, and Spain. Aside from the constant term and the lagged dependent variable, the only explanatory variable in the Austrian interest rate reaction function is the Ger- 
man short-term interest rate. For France and Belgium the only two additional explanatory variables are the German and US interest rates, and for Spain the only additional variable is the US interest rate. More will be said about the use of the interest rate reaction functions in Section 4.

There is an estimated exchange rate equation per country. For Germany and all the non-European countries, the dependent variable is the exchange rate vis-à-vis the US dollar. For these countries, the exchange rate depends on the price level of the country relative to the US price level and the short-term interest rate of the country relative to the US interest rate. For the European countries except Germany, the dependent variable is the exchange rate visà-vis the D-mark. For these countries the exchange rate depends on the price level of the country relative to the German price level and the short-term interest rate of the country relative to the German interest rate.

There are also estimated equations explaining the demand for money, the forward exchange rate, employment, the labour force of men, and the labour force of women. These will not be discussed here.

In a given trade-share equation, the share of country i's total imports imported from country $j$ depends on the price of country $j$ 's exports relative to a price index of all the other countries' export prices. The trade-share equations are in US dollars, and all export prices are converted to dollar prices using the exchange rates. The restriction that the sum of all exports equals the sum of all imports is imposed in the model.

\section{The Effects of an Interest Rate Decrease}

To help in understanding the results, it will be useful to discuss the effects of a decrease in the short-term interest rate in a country. A decrease in the short-term rate leads to a decrease in the long-term rate through the term structure equation. A decrease in the short-term rate also leads to a depreciation of the country's currency (assuming that the interest rate decrease is relative to other countries' interest rates). The interest rate decreases lead to an increase in consumption, investment, and imports. The depreciation of the currency leads to an increase in exports. This effect on exports works through the trade-share equations. The dollar price of the country's exports that feeds into the trade-share equations is lower because of the depreciation, and this increases the share of the other countries' total imports imported from the particular country. The effect on aggregate demand in the country from the interest rate decrease is thus positive from the increase in consumption, investment, and exports and negative from the increase in imports. The net effect could thus go either way, but it is almost always positive.

There is also a positive effect on inflation. The depreciation leads to an increase in the price of imports, and this has a positive effect on the domestic price level through the price equation. In addition, if aggregate demand increases, this increases demand pressure, which has a positive effect on the domestic price level.

There are many other effects that follow from these, including effects back on the short-term interest rate itself through the interest rate reaction function, but these are typically second order in nature, especially in the short run. The main effects are as just described.

\section{More Details on the Model}

There is a mixture of quarterly and annual data in the MC model. Quarterly equations are estimated for 14 countries (the first 14 in note 3 ), and annual equations are estimated for the remaining 19. However, all the trade-share equations are quarterly. There are quarterly data on all the variables that feed into the trade-share equations, namely the exchange rate, the local-currency price of exports, and the total value of imports per country. When the model is solved, the predicted annual values of these variables for the annual countries are converted to predicted quarterly values using a simple distribution assumption. The quarterly predicted values from the trade-share equations are converted to annual values by summation or averaging when this is needed.

There are 16 European countries in the model, eight quarterly and eight annual. The following discussion will focus on eight of these: Germany, Italy, the Netherlands, the United Kingdom, Austria, France, Belgium, and Spain. Belgium and Spain are annual countries, and the others are quarterly. The other eight countries (Switzerland, Finland, Denmark, Norway, Sweden, Greece, Ireland, and Portugal) have very small or zero estimated interest-rate effects on aggregate demand, and so these countries are not much affected by a switch of monetary-policy regimes. The results for these eight countries are in general not as good as those for the other European countries, and so probably not much confidence should be placed on the small estimated interest-rate effects in these countries. These small effects may simply be due to poor data or too few observations. In other words, it may be that these countries would be importantly affected by the move to a common European currency, but that the econometric work is not good enough to pick this up.

Total European output as used below is denominated in D-marks and is the sum of the output of all 16 European countries. The European price level is defined to be the ratio of nominal to real European output. ${ }^{(6)}$

\section{The Stochastic Simulation Experiments}

Since the main exercise of this article is to estimate and compare economic variability in the current regime and in the EMU regime, one needs a measure of economic vari- 
ability and a way of calculating it. The approach taken in this article is as follows.

Of the 328 stochastic equations, 189 are quarterly and 139 are annual. There is an estimated error term for each of these equations for each period. Although the equations do not all have the same estimation period, the period 1972-1994 is common to almost all equations. ${ }^{[7]}$ There are thus available 23 vectors of annual error terms and $92 \mathrm{vec}-$ tors of quarterly error terms. These vectors are taken as estimates of the economic shocks, and they are drawn in the manner discussed below. Note that these vectors pick up historical correlations of the error terms. If, for example, German, French, and Italian consumption shocks are highly positively correlated, the error terms in the three consumption equations will tend to be all high together or all low together.

The period used for the variability estimates is 1989:11994:4, six years or 24 quarters. This study is concerned with stabilization around some base path and not with the position of the base path itself, and it does not matter much which path is chosen for the base path. The choice here is simply to take as the base path the historical path. If the estimated errors for 1989:1-1994:4 are added to the model and taken to be exogenous, the solution of the model for this period using the actual values of all the exogenous variables is the perfect tracking solution. For all the stochastic simulations below, the estimated errors for 1989:1-1994:4 are added to the model and the draws are around these errors. This means that all the draws are around the historical path.

Each trial for the stochastic simulation is a dynamic deterministic simulation for 1989:1-1994:4 using a particular draw of the error terms. For each of the six years for a given trial an integer is drawn between 1 and 23 with probability $1 / 23$ for each integer. This draw determines which of the 23 vectors of annual error terms is used for that year. The four vectors of quarterly error terms used are the four that correspond to that year. Each trial is thus based on drawing six integers. The solution of the model for this trial is an estimate of what the world economy would have been like had the particular drawn error terms actually occurred. (Remember that the drawn error terms are on top of the actual error terms for 1989:1-1994:4, which are always used.) By using the estimated error terms for the draws, the trials are consistent with the historical experience: the estimated error terms are data determined. ${ }^{(8)}$ The number of trials taken is 100 , so 100 world economic outcomes for 1989:1-1994:4 are available for analysis. ${ }^{(9)}$

Let $y_{t}^{j}$ be the predicted value of endogenous variable $y$ for quarter or year $t$ on trial $j$, and let $y_{t}$ be the base-path (actual) value. How best to summarize the $100 \times 24$ or 100 $\times 6$ values of $y_{t}^{j}$ ? One possibility for a variability measure is to compute the variability of $y_{t}^{j}$ around $y_{t}$ for each $t:(1 / J) \sum_{j=1}^{J}\left(y_{t}^{j}-y_{t}^{*}\right)^{2}$, where $J$ is the total number of trials. ${ }^{(10)}$ The problem with this measure, however, is that there are either 24 or 6 values per variable, which makes summary difficult. A more useful measure is the following. Let $L^{i}$ be:

$$
L^{i}=\frac{1}{T} \sum_{i=1}^{T}\left(y_{i}^{j}-y_{t}^{*}\right)^{2}
$$

where $T$ is the length of the simulation period $(24$ or 6 in the present case). Then the measure is

$$
L=\sqrt{\frac{1}{J} \sum_{j=1}^{J} L^{j}}
$$

$L$ is a measure of the deviation of the variable from its base values over the whole period, and because the square root is taken, it is in units of the standard deviation of the variable. ${ }^{(11)}$

\section{Variability Estimates for the Current Regime}

Values of $L$ for four variables, ten countries plus total Europe, and four experiments are presented in Table 1. The two non European countries are the United States and Japan. The four variables are real output, inflation, the shortterm interest rate, and the exchange rate per country. For inflation and the interest rate the values used in the calculation of $L$ in (1) are in percentage points (a five per cent interest rate is 5.0 ). For real output and the exchange rate the calculation of $L$ is

$$
L^{i}=\frac{1}{T} \sum_{i=1}^{T}\left[100\left(y_{t}^{j}-y_{t}^{*}\right) / y_{t}^{*}\right]^{2}
$$

where $y$ is the level of the variable. Multiplying by 100 puts the values of $L$ in Table 1 in percentage points for real output and the exchange rate. Even though results for only ten countries are presented in the table, the entire MC model is used for the experiments. The same draws were used for each experiment in order to lessen stochastic-simulation error for the comparisons between experiments. The rest of this article is essentially a discussion of Table 1.

For all the experiments the drawn error terms are not used for the short-term interest rate and exchange rate equations. Since these equations are interpreted as policy reaction functions in the model, it seemed best to take them as rules with no stochastic shocks. In addition, the drawn error terms are not used for the long-term interest rate equations (the term structure equations) for the European countries. Since moving from the current regime to the EMU regime requires changing these equations for the European countries, it seemed best for comparison purposes not to complicate matters by having to make assumptions about what errors to use in the EMU regime for these equations. The variability estimates are thus based on all types of shocks except financial ones. 
Table 1. Values of $L$ for Four Experiments

\begin{tabular}{|c|c|c|c|c|c|c|c|c|c|c|}
\hline & \multirow{2}{*}{\multicolumn{6}{|c|}{ Experiment }} & \multirow{2}{*}{\multicolumn{4}{|c|}{$\begin{array}{c}\text { Inflation } \\
\text { Experiment }\end{array}$}} \\
\hline & & & & & & & & & & \\
\hline & 1 & 2 & 3 & 4 & $(4 / 2)^{2}$ & $(4 / 3)^{2}$ & 1 & 2 & 3 & 4 \\
\hline $\mathrm{GE}$ & 1.87 & 1.16 & 1.15 & 1.49 & 1.65 & 1.68 & 0.81 & 0.72 & 0.72 & 0.72 \\
\hline IT & 2.64 & 2.21 & 2.19 & 2.52 & 1.30 & 1.32 & 2.14 & 2.05 & 2.05 & 1.95 \\
\hline $\mathrm{NE}$ & 3.33 & 3.19 & 3.16 & 2.96 & 0.86 & 0.88 & 2.14 & 2.14 & 2.14 & 2.14 \\
\hline UK & 2.32 & 2.11 & 2.10 & 2.11 & 1.00 & 1.01 & 3.89 & 3.88 & 3.88 & 3.86 \\
\hline $\mathrm{AU}$ & 4.91 & 4.07 & 2.85 & 3.95 & 0.94 & 1.92 & 4.45 & 4.01 & 3.49 & 3.96 \\
\hline FR & 1.54 & 1.49 & 1.15 & 1.34 & 0.81 & 1.36 & 1.60 & 1.62 & 1.60 & 1.58 \\
\hline $\mathrm{BE}$ & 4.11 & 3.71 & 3.23 & 3.60 & 0.94 & 1.24 & 1.33 & 1.34 & 1.24 & 1.28 \\
\hline SP & 1.66 & 1.61 & 1.35 & 1.62 & 1.01 & 1.44 & 2.44 & 2.20 & 1.93 & 1.99 \\
\hline US & 1.67 & 1.64 & 1.64 & 1.63 & & & 1.12 & 1.13 & 1.13 & 1.13 \\
\hline $\mathrm{JA}$ & 2.99 & 2.99 & 2.98 & 3.00 & & & 2.05 & 2.05 & 2.05 & 2.05 \\
\hline \multicolumn{7}{|c|}{ Short-term Interest Rate } & \multicolumn{4}{|c|}{ Exchange Rate } \\
\hline $\mathrm{GE}$ & 0 & 1.26 & 1.27 & - & & & 3.27 & 2.66 & 2.69 & - \\
\hline IT & 0 & 2.12 & 2.11 & - & & & 3.46 & 2.69 & 2.71 & - \\
\hline NE & 0 & 1.49 & 1.50 & - & & & 3.35 & 2.70 & 2.73 & - \\
\hline UK & 0 & 2.13 & 2.13 & - & & & 4.09 & 3.86 & 3.86 & - \\
\hline $\mathrm{AU}$ & 0 & 0.70 & 1.45 & - & & & 3.66 & 3.00 & 2.91 & - \\
\hline FR & 0 & 1.28 & 0.69 & - & & & 4.71 & 3.75 & 3.74 & - \\
\hline $\mathrm{BE}$ & 0 & 1.12 & 1.65 & - & & & 3.25 & 2.72 & 2.74 & - \\
\hline SP & 0 & 0.58 & 0.96 & - & & & 6.00 & 3.24 & 2.97 & - \\
\hline US & 1.22 & 1.22 & 1.22 & 1.21 & & & - & - & - & - \\
\hline JA & 0.70 & 0.70 & 0.70 & 0.69 & & & 3.29 & 3.31 & 3.31 & 3.29 \\
\hline $\mathrm{EU}$ & - & - & - & 1.21 & & & - & - & - & 2.52 \\
\hline
\end{tabular}

Note:

$1=$ all European interest rates exogenous.

2 = estimated interest rate reaction functions used.

3 = same as 2 except the rule in (3) used for Austria, France, Belgium, and Spain.

$4=$ EMU regime.

$\mathrm{GE}=$ Germany, IT $=$ Italy, NE $=$ the Netherlands, $\mathrm{UK}=$ the United Kingdom, $\mathrm{AU}=$ Austria, FR $=$ France,

$\mathrm{BE}=$ Belgium, $\mathrm{SP}=\mathrm{Spain}, \mathrm{US}=$ the United States, $\mathrm{JA}=$ Japan, $\mathrm{EU}=$ Total Europe.

For the first experiment all the European interest rate reaction functions are dropped from the model, and the European short-term interest rates are taken to be exogenous. This is not meant to be a realistic case, but merely to serve as a baseline for comparison. The results are in the first column for each variable in Table 1 . The second experiment differs from the first in that the European interest rate reaction functions are added back in. Otherwise, everything else is the same. The results are presented in the second column for each variable.

Comparing columns 1 and 2 for output shows how stabilizing the estimated interest rate reaction functions are. For Germany $L$ falls from 1.87 to 1.16 , and so the German interest rate reaction function is quite stabilizing. $L$ also falls for the other European countries, and so in general the reaction functions are stabilizing. The fact that the reaction functions for Austria, France, Belgium, and Spain are stabilizing means that the US and German reaction functions have some stabilizing influence on these countries. (Re- member that the only explanatory variables in these four reaction functions aside from the constant term and the lagged dependent variable are the German and/or US interest rates.) France and Spain, however, are not helped very much. For France $L$ falls only from 1.54 to 1.49 , and for Spain $L$ falls only from 1.66 to 1.61 .

Exchange rate variability falls for the European countries when the interest rate reaction functions are added. This is primarily because of Germany. The US interest rate appears in the German interest rate reaction function, and when the reaction function is dropped, the German rate less closely follows the US rate. The greater variability of the German rate relative to the US rate when the reaction function is dropped leads to greater variability of the German exchange rate because the German interest rate relative to the US interest rate is an explanatory variable in the German exchange rate equation. The greater variability of the German exchange rate then leads to greater variability of the other European exchange rates (vis-à-vis the US dol- 
lar) because the other exchange rates fairly closely follow the German exchange rate in the short run.

The differences in $L$ for inflation in Table 1, column 1 versus column 2 , are fairly small, and it is clear that the reaction functions stabilize output much more than they do inflation. In the price equations the price responses to output changes are generally fairly small, and so making output more stable has only a small effect on making inflation more stable. There is also a stabilizing effect on inflation from making the exchange rate more stable, but again this effect is fairly small. A country's exchange rate affects its domestic price level because its import price level is an explanatory variable in the domestic price equation.

\section{Results Using Alternative Monetary Policy Rules}

Although experiment 2 uses the estimated interest rate reaction functions, the present methodology does not require that they be used. Alternative monetary policy rules can be substituted for the estimated rules. An interesting question in this regard is whether my inability to find significant domestic explanatory variables in the Austrian, French, Belgium, and Spanish interest rate reaction functions reflects actual behaviour of the monetary authorities or is simply due to specification error. If the estimated rules are highly misspecified, it is of interest to examine other rules.

To examine the sensitivity of the results to the use of the estimated reaction functions for these four countries, a different function was postulated for each country:

$$
R_{t}=R_{t}^{*}+.5 \times 100\left(Y_{t}-Y_{t}^{*}\right) / Y_{t}^{*}+.25 \times 100\left(\dot{P}_{t}-\dot{P}_{t}^{*}\right)
$$

where $R$ is the short-term interest rate, $Y$ is the level of real output, and $\dot{P}$ is the percentage change in domestic price level at an annual rate. The starred values are the base (actual) values. According to this rule, the interest rate differs from its base value as output and inflation differ from theirs. This rule, including the .5 and .25 weights, was used in Fair (1997c) for the United States, and it has been taken unchanged for use here. No experimenting was done here with different weights. Also, note that the US and German interest rates are not included in the rule, contrary to the estimated rules.

The results using the rule in (3) are presented in the third columns in Table 1. The third experiment differs from the second only in that the estimated interest rate reaction functions for France, Austria, Belgium, and Spain are replaced by the rule in (3). The results for output show that the new rules are considerably more stabilizing for these four countries. For France, for example, $L$ falls only from 1.54 to 1.49 using the estimated rule but from 1.54 to 1.15 using the new rule. The results for the third experiment thus suggest that the monetary authorities of these four countries could do better than follow the reaction function that I have estimated they follow. They may, of course, in fact do better, since the estimated reaction functions may not be good approximations of their actual behaviour. The importance of these results for present purposes is that there are two possible experiments to use for comparison with the EMU regime experiment.

One could, of course, also replace the estimated rules for Germany, Italy, the Netherlands, and the United Kingdom by the rule in (3). This was not done for experiment 3 because the estimated rules for these countries were stabilizing (experiment 2 versus 1). Although not reported in Table 1, the experiment was in fact run in which the estimated rules for these four countries were replaced by the rule in (3). Otherwise, everything was the same as for experiment 3. For Germany the value of $L$ for output was 1.16, which compares to 1.15 for experiment 3 in Table 1. The estimated interest rate reaction function and the rule in (3) for Germany thus have very similar stabilization properties. The results were also close for the Netherlands (3.07 versus 3.16 for experiment 3) and for the United Kingdom (2.05 versus 2.10 for experiment 3 ). For Italy the rule in (3) was somewhat better (1.83 versus 2.19 for experiment 3 ), although both rules are considerably better than no rule for Italy (2.64 for experiment 1$)$. These results are thus interesting in showing the properties of the estimated rules for the four countries are similar to the properties of the rule in (3).

\section{A Digression on Policy Coordination}

This article has perhaps something quantitative to contribute to the literature on international policy coordination that began with the work of Niehans (1968) and Hamada (1974). In the MC model the monetary authorities of different countries do not play games with each other, but instead follow simple rules (the estimated interest rate reaction functions). Since the US interest rate appears in a numbet of the other reaction functions, the United States has a leadership role. Also, Germany has a leadership role within Europe because the German interest rate appears i a number of the other European reaction functions.

The question that can be addressed using the methodology of this article is whether the stabilization behaviour of one country helps or hurts the stabilization behaviour of other countries. To check this with respect to the United States, experiment 2 was rerun with the US interest rate reaction function dropped and the US short-term interest rate taken to be exogenous. In this case the United States does not stabilize, but all the other countries follow their estimated reaction functions. The value of $L$ for output for the United States rose from 1.64 (column 2 in Table 1) to 1.96 (not shown in Table 1). This shows that the estimated 
US interest rate reaction function is stabilizing for the United States. However, the value of $L$ fell for Germany, from 1.16 to 1.02 . Germany is thus better off when the United States does not stabilize, and one has a quantitative estimate of by how much.

Why is Germany hurt when the United States stabilizes? Consider a shock (such as a positive consumption shock) in the United States that leads the US interest rate to increase when the US reaction function is in. This leads the German interest rate to increase, although not by as much as the US rate, and so the D-mark depreciates. German output is thus affected-positively if the effect of the depreciation outweighs the effect of the interest rate increase. German output thus responds to US shocks through US interest rate changes, and if US interest rate changes are turned off, there is less output variability from this source.

The United Kingdom is also hurt by US stabilization, where $L$ falls from 2.11 (column 2 in Table 1 ) to 2.00 (not shown). Italy, France, Spain, and Japan are little affected. The Netherlands, Austria, and Belgium are actually helped. For the Netherlands, for example, $L$ rises from 3.19 (column 2 in Table 1) to 3.46 (not shown). These countries are helped basically because Germany is hurt. For example, when Germany stabilizes well this hurts the Netherlands (just as when the United States stabilizes well this hurts Germany), and so the Netherlands is better off when Germany does not stabilize as well, which is when the United States stabilizes. Having the United States stabilize thus helps the Netherlands.

More experiments could be done, dropping different reaction functions, but this should give a flavor of the kinds of questions that can be considered using the present methodology. Note that no optimization is going on here. Each country is merely following the reaction function that it has been estimated to follow.

\section{The Assumed EMU Regime}

As noted in Section 1, there are many possible EMU regimes that could be postulated. The methodology of this article does not depend on any one particular choice. For the regime used here all 16 European countries in the model were included. The following three changes were made to the $\mathrm{MC}$ model to move to the EMU regime.

First, the interest rate reaction functions for all the European countries except Germany were dropped, and their short-term interest rates were assumed to move one for one with the German rate. The domestic variable that is included in the estimated German reaction function is the German output gap, and this variable was replaced by the European output gap. ${ }^{[12]}$ The coefficient estimates in this equation were not changed, and the US interest rate, which is an explanatory variable in the equation, was retained. The behaviour of the European monetary authority is thus assumed to be the same as the historically estimated behaviour of the Bundesbank except that the response is now to total European output instead of just German output.

Second, the long-term interest rate equations (the term structure equations) for all the European countries except Germany were dropped, and their long-term interest rates were assumed to move one for one with the German rate. The long-term German interest rate equation was retained as is. The only explanatory variables in this equation are the lagged value of the long-term rate and the current value and lagged values of the short-term rate.

Third, the exchange rate equations for all the European countries except Germany were dropped, and their exchange rates were fixed to the German rate. The German exchange rate equation has as explanatory variables the German price level relative to the US price level and the German short-term interest rate relative to the US shortterm interest rate. This equation was used as is except that the German price level was replaced by the European price level. (The German short-term interest rate is now, of course, the European short-term interest rate, as discussed above.)

No other changes were made to the model. To summarize, then, in this assumed EMU regime, the two main changes are 1) the postulation of a European interest rate reaction function that responds to the European output gap and 2) the postulation of an exchange rate equation for the common European currency that responds to the European price level relative to the US price level and the European short-term interest rate relative to the US shortterm interest rate.

\section{Results for the EMU Regime}

The results for the EMU regime are presented in the fourth columns in Table 1. The following conclusions can be gleaned from the results.

1. Comparing columns 1 and 4, output variability is less in the EMU regime that it would be in the regime in which there were no European interest rate reaction functions. The European interest rate reaction function in the EMU regime is thus stabilizing relative to no rules at all.

2. Comparing columns 2 and 4 , output variability is greater in the EMU regime than in the current regime for Germany and Italy and either essentially the same or smaller for the other European countries. To see how much each country is hurt or helped in going from column 2 to 4 , column 5 presents the ratio of the square of $L$ in column 4 to the square of $L$ in column 2. (The square of $L$ is in units of variances, and so the ratio measures the per cent increase in a variance-like variable.)

It is clear that Germany loses the most in mov- 
ing to the EMU regime, with variability rising by 65 per cent. In the non EMU regime the German interest rate reaction function does a fairly good job in stabilizing German output, responding to the German output gap, and in the EMU regime the reaction function only responds to the German output gap to the extent that it is part of the total European output gap. The European monetary authority thus does not do as good a job at stabilizing Germany as the Bundesbank does. (Does this help explain why German polls show the Germans not very favorable toward the EMU?)

The country that benefits the most from moving to the EMU regime is France, and it is easy to see why. Columns 1 and 2 show that the estimated French reaction function is a poor stabilization rule: the French are essentially estimated not to stabilize. Thus, France gains in the EMU regime because there is a stabilization rule that it benefits from, namely the overall European rule. If the French by themselves are not going to stabilize, they are better off joining a group that at least in part responds to French shocks. (Does this help explain why French polls show the French favorable toward the EMU?) Except for Italy, where the Italian estimated rule does better than the EMU rule (variability is 30 per cent higher for Italy), the EMU rule does the same as or better than the country-specific estimated rules for the other European countries.

3. When the rule in (3) is used for Austria, France, Belgium, and Spain instead of the estimated interest rate reaction functions (column 3 versus 4), output variability is noticeably greater in the EMU regime for all four countries. For example, the results show that if France followed the rule in (3) instead of its estimated rule, it would be hurt instead of helped by moving to the EMU (variability is 36 per cent higher). The rule in (3) is more stabilizing for France than is the EMU rule. Overall, experiment 3 shows that the results are clearly sensitive to the choice of the monetary policy rule. The better is an individual rule, the greater is the cost of moving to the EMU regime.

Figure 1 provides another way of looking at the differences across regimes. Consider output variability. Each experiment yields 2400 per cent output deviations $\left(100\left(y_{t}^{j}-y_{t}^{*}\right) / y_{t}^{*}\right)$, since there are 24 quarters per trial and 100 trials, and $L$ is one measure of variability of these values. Another possibility is to compute a histogram of these values, and this is what is done in Figure 1 for Germany. The first histogram is for experiment 2 (the current regime), and the second is for experiment 4 (the EMU regime). It is clear that the values are more scattered for the EMU regime, and the figure gives a visual sense of how much.

\section{Conclusion}

This study has presented a methodology for examining the stabilizations costs of the EMU, and Table 1 provides quantitative estimates of these costs. These estimates are clearly preliminary, and there are a number of extensions that would be interesting to pursue in future work. First, although the estimates in Table 1 are based on the assumption that all of Europe joins the EMU, it would be easy to examine subsets of joiners.

Second, and perhaps most important, it would be interesting to examine alternative monetary policy rules. So far only the estimated rules (the estimated interest rate reaction functions), which are just estimates of average past behaviour, and the simple rule in (3) have been used. One could, for example, search over different weights in (3) for a given country to find a good stabilizing rule, and more target variables could be added if desired. The better the rule for a given country, the larger are the stabilization costs of joining the EMU. On the other hand, one could

Figure 1. Histograms of 2400 German Output Deviations

\section{Current Regime}

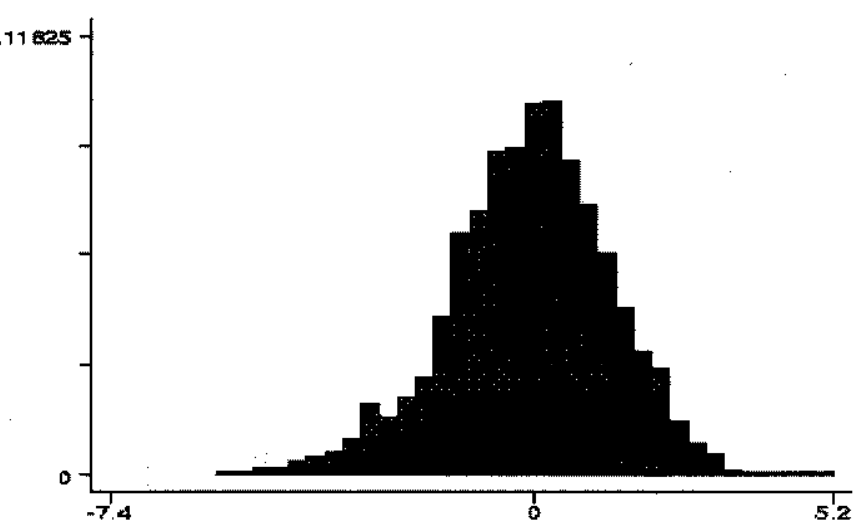

\section{EMU Regime}

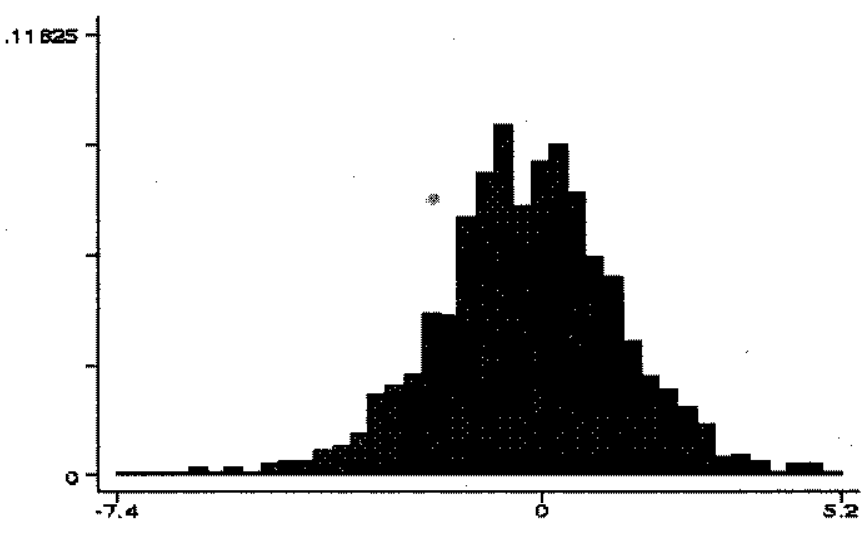


also search for a better rule in the EMU regime. So far the only EMU rule used is the estimated German rule with European variables replacing German ones. Instead, one could try a rule like (3) for the EMU and search over the weights.

A third issue to consider is whether after moving to the EMU regime the policy authorities in a country would try to use fiscal policy for stabilization purposes. For the results in this article fiscal policy has been taken to be exogenous. A tax-rate rule is proposed in Fair (1997c) for the United States that is an effective stabilizer, and if a rule like this were used by a European country after joining the EMU, it would lower the stabilization costs estimated here. ${ }^{(13)}$ It thus may be of interest to try some fiscal-policy rules in the EMU regime, although in doing so one would have to take into account the rather strict fiscal-policy constraints that are imposed on countries that join the EMU.

There are some possible biases in the Table 1 estimates that are more difficult to examine. There is, for example, no labour mobility in the model, and to the extent that there is labour mobility between countries in Europe the real stabilization costs are likely to be smaller than those in Table 1. It would be difficult to modify the MC model to try to account for labour mobility. Also, if the change in regimes results in the shocks across countries being more highly correlated than they were historically, this is likely to bias the current cost estimates upwards. The more highly correlated are the shocks, the more is the common European monetary policy rule likely to be stabilizing for the individual countries. It would be difficult to try to estimate how the historical correlations might change.
It may also be the case that the historical shocks used for the stochastic-simulation draws are too large. The shocks are estimated error terms in the stochastic equations, and they reflect both pure random shocks and possible misspecification. However, if the shocks are too large, it is not clear how the cost estimates in Table 1 would be affected since the values of $L$ would go down for all experiments.

Another issue to consider is whether the EMU regime would increase credibility. If, for example, Italian longterm interest rates were lower after Italy joined the EMU (because Italian policy was then more credible), this could have a beneficial effect on Italian growth. Level effects of this sort are not taken into account in this study, since only stabilization costs are being estimated.

Finally, it may be the case that the MC model is such a poor approximation of the world economy that no results from it are worth considering. Some people have such a low opinion of structural macroeconometric models that they put no weight on any tests of them or results using them. I find this frustrating since one of the main themes of my research has been the testing of such models, and I wish there were more interest in testing. The stochastic equations of the $\mathrm{MC}$ model have been extensively tested, and these tests are reported in Chapter 6 in Fair (1994), in Fair (1997a, 1997b), and on the website. In addition, the accuracy of the overall model has been examined, and these results are discussed in Chapter 9 in Fair (1994). Based on these results I would argue that the $\mathrm{MC}$ model is accurate enough to warrant taking seriously the results in Table 1.

\section{NOTES}

(1) For other results using stochastic simulation to examine the EMU, see Hallett, Minford, and Rastogi (1993), Masson and Symansky (1992), and Masson and Turtelboorn (1997).

(2) In a few cases a coefficient is constrained to be equal to a particular value, and in these cases the other coefficients in the equation are estimated by 2 SLS or OLS subject to this constraint.

(3) The 33 countries are the United States, Canada, Japan, Austria, France, Germany, Italy, the Netherlands, Switzerland, the United Kingdom, Finland, Australia, South Africa, Korea, Belgium, Denmark, Norway, Sweden, Greece, Ireland, Portugal, Spain, New Zealand, Saudi Arabia, Venezuela, Colombia, Jordan, Syria, India, Malaysia, Pakistan, the Philippines, and Thailand.

(4) The 12 other countries that fill out the trade-share matrix are Nigeria, Algeria, Indonesia, Iran, Iraq, Kuwait, Libya, the United Arab Emirates, Israel, Bangladesh, Singapore, and an all other category.

(5) All the variables and equations in the model are presented in Appendices A and B of The MC Model Workbook on the website. All the coefficient estimates are presented in the "Chapter 5 Tables" and "Chapter 6 Tables" that follow the appendices. The estimated interest rate reaction function for a country is equation 7 for that country (except for the United States, where it is equation 30), and the estimated exchange rate equation is equation 9. Various test results for each equation are presented along with the coefficient estimates.

For a given European country $i$ and period $t$, let $Y_{i t}$ be its real output, $P_{i t}$ its domestic price level, and $e_{i t}$ its exchange rate visà-vis the mark. Also, let $e_{i g}$ be its exchange rate in 1990, the base year for real output. Then total European nominal output is $\sum_{i=1}^{16}\left(P_{i t} Y_{i t}\right) / e_{i t}$ and total European real output is $\sum_{i=1}^{16} y_{i t} / e_{i j} 90$. For the annual countries, the annual values of $Y, P$, and $e$ were converted to quarterly values for these calculations, again using a simple distribution assumption. For the few equations whose estimation periods began later or ended earlier than the 1972-1994 period, zero errors were used for the missing observations.

Another way of drawing error terms would be from an estimated distribution. Let $\hat{V}$ be an estimate of the $328 \times 328$ covariance matrix $V$ of the error terms. One could, for example, assume that the error terms are multivariate normal and draw errors from the $N\left(\hat{\mu}_{t}, \hat{v}\right)$ distribution, where $\hat{\mu}_{t}$ is the vector of the historical errors for $t$. Because of the quarterly- 
annual difference, $\hat{V}$ would have to be taken to be block diagonal, one quarterly block and one annual block. Even for this matrix, however, there are not enough observations to estimate all the nonzero elements, and so many other zero restrictions would have to be imposed. The advantage of drawing the historical error vectors is that no distributional assumption has to be made and no zero restrictions have to be imposed.

(9) The solution of the MC model, which is explained in Fair (1994), is a somewhat involved task, and trials are costly in terms of computer time. For a simulation period of 24 quarters, 100 trials takes about 21 minutes on a Pentium Pro 200 computer. No solution failures on any trial occurred for the stochastic simulations reported in Table 1.

(10) If $y_{t}^{*}$ were the estimated mean of $y_{t}$, this measure would be the estimated variance of $y_{t}$. Given the $J$ values of $y_{t}^{j}$, the estimated mean of $y_{t}$ is $(1 / J) \sum_{t=1} y_{t}^{j}$, and for a nonlinear model it is not the case that this mean equals $y_{t}^{*}$ even as $J$ goes to infinity. As an empirical matter, however, the difference in these two values is quite small for almost all macroeconometric models, and so it is approximately the case that the above measure of variability is the estimated variance.

(11) $L$ is, of course, not an estimated standard deviation. Aside from the fact that for a nonlinear model the mean of $y_{2}$ is not $y_{t}^{*}$, $L$ is an average across a number of quarters, and variances are not in general constant across time. $L$ is just a summary measure of variability.

(12) Continuing from note 6 , total European potential output is defined to be $\sum_{i=1}^{16} Y S_{i t} / e_{i} 90$, where $Y S_{\text {it }}$ is the potential output of country $i$ for period $t$. The output-gap variable used is the per cent deviation of actual European output from potential European output.

(13) Regarding the policy coordination discussion at the end of Section 4, the US tax-rate rule in Fair (1997c) affects other countries much less than does the US monetary-policy rule. Experiments like those in Table 1 run with and without the US tax-rate rule (and with the US short-term interest rate exogenous) show small differences in the $L$ values for other countries. Unless the US interest rate is changed, there are small effects on other countries' exchange rates, which lead to smaller overall effects on the other countries' output.

\section{REFERENCES}

Fair, Ray C. (1994), Testing Macroeconometric Models, Cambridge, MA: Harvard University Press.

Fair, Ray C. (1997a), 'Testing the NAIRU model for the United States', April.

Fair, Ray C. (1997b), 'Testing the NAIRU model for 27 Countries', April.

Fair, Ray C. (1997c), 'A fiscal-policy rule for stabilization', June.

Hallett, Andrew Hughes, Patrick Minford, and Anupam Rastogi (1993), 'The European Monetary System: achievements and survival', in Bryant, Ralph C., Peter Hooper, and Catherine L. Mann, eds., Evaluating Policy Regimes: New Research in Empirical Macroeconomics, Washington, D.C.: The Brookings Institution, pp. 617-668.

Hamada, Koichi (1974), "Alternative exchange rate systems and the interdependence of monetary policies," in Robert Z. Aliber, ed., National Monetary Policies and the International Financial System, Chicago: University of Chicago Press, pp. 13-33.

Kenen, Peter B. (1969), 'The theory of optimum currency areas', in Mundell, Robert A., and Alexander A. Swoboda, eds., Monetary Problems of the International Economy, Chicago: University of Chicago Press, pp. 41-60.

Masson, Paul R., and Stephen Symansky (1992), 'Evaluating the EMS and EMU using stochastic simulations: some issues', in Barrell, Ray, and John Whitley, eds., Macroeconomic Policy Coordination in Europe: The ERM and Monetary Union, London: Sage Publications, pp. 12-34.

Masson, Paul R., and Bart G. Turtelboom (1997), 'Characteristics of the Euro, the demand for reserves, and policy coordination under the EMU', in Masson, Paul R., Thomas H. Krueger, and Bart G. Turtelboom, EMU and the International Monetary System, Washington, D.C.: International Monetary Fund, pp. 194-224.

McKinnon, Ronald (1963), "Optimum currency areas', American Economic Review, vol. 53, pp. 717-725.

Mundell, Robert A. (1961), 'A theory of optimum currency areas', American Economic Review, vol. 50, pp. 657-665.

Niehans, Jürg (1968), 'Monetary and fiscal policies in open economies under fixed exchange rates: an optimizing approach', Journal of Political Economy, vol. 76, pp. 893-920.

von Hagen, Jürgen, and Manfred J. M. Neumann (1994), 'Real exchange rates within and between currency areas: how far away is the EMU?', Review of Economics and Statistics, vol. 76, pp. 236-244.

Wyplosz, Charles (1997), 'EMU: why and how it might happen', Journal of Economic Perspectives, vol. 11, pp. 3-22. 